\title{
Behind the Themes and Between the Lines: Moving Beyond Scientific Misconduct to Higher Ground
}

Ethics is rarely publicly discussed in materials research circles or covered on the pages of MRS Bulletin. In fact, a few years ago, MRS Bulletin considered starting a department on ethical issues, but it did not gain steam due to the lack of available content. This is something for which the materials community should be proud, but current events remind us that we can never rest on our laurels.

In RESEARCH/RESEARCHERS (page 834), we cover the report that found Hendrik Schön responsible for scientific misconduct in a series of published papers. While the report gave a definitive end to the investigation, it brought to the fore additional questions.

After a finding of scientific misconduct that permeated so many highly respected sources, how do we reassess the relevant scientific knowledge base? What has been verified by other, more credible, data? What is reasonable, but needs to be retested? What is still a far stretch, but worth stretching to attain? And what needs to be cast aside as invalid or even impossible? It is much easier to build knowledge than to whittle it away, but we must move back to what is known, but no further, and then continue the climb once more.

Once the scientific base regains its bearings, how do we go forward with rapid enthusiasm and realistic assessment? What codes of ethics are assumed or are in place to ensure the long-term integrity and viability of our scientific foundation, and are they upheld? While such codes develop over time, we can take this opportunity to step back, gather the collective knowledge and best practices that already exist, and then embark on the path to higher ground.

We can start with the satisfaction that the scientific process of review and validation did eventually unearth the misconduct in this high-profile case. Also, Bell Labs can be commended for taking rapid action to investigate and report on the misconduct allegations.
However, while the system caught the misconduct, the community has not escaped unscathed. How long and how much energy will it take to correct the course? What can co-authors, management, and reviewers do as we go forward to sniff out and snuff out misconduct earlier as well as to intercept more common human error?

In materials science, where "interdisciplinarity" is its essence, the responsibilities of co-authors have become complex. By design, our field encourages researchers with vastly different expertise and capabilities to work together to solve problems too big for an individual to do alone. It is not possible for all authors to be experts on the data taken by all of their colleagues, and thus we must collaborate with a degree of trust. However, this is also why a co-author should enter as a full participant, with eyes wide open. Collaboration is more than just "I do this, you do that." There needs to be understanding and interaction at the interface (the essence of MRS, from my perspective). As specialists in a field of diversity, it behooves us all to step a little outside of our expertise to learn at the interfaces. Particularly when the stakes are high, the standard of proof should rise, too. Perhaps it is not possible in every case, but for surprising and groundbreaking results, one should share data with colleagues to encourage mutual responsibility and understanding. Those closest to the work are generally best able to challenge it. Even rising stars and long-time pros make mistakes, falter, or downright fail. As they say in the economic community, "Past results are not a guarantee of future performance." In strengthening collaborations, we must be open, careful, diligent, and alert.

While co-authors may be the first line of defense, the professional responsibility does not stop there. Each layer of assessment and review should add a level of quality, rather than serve as a rubber stamp. With the huge quantities of data that now can be collected, and combinatorial methods that process tremendous numbers of samples, and the push to publish, patent, please shareholders and raise funds, have demands exceeded our capacity? This is not just about catching misconduct. It is about creating quality. Can't we do better? Fraud and error are both disruptive, and we should do what we can to reduce both at all levels of our community.

Management may need to review its expectations of employees and its procedures for retention of data, preservation of samples, and review of work by colleagues. Peer-reviewed journals should re-examine their review policies and see that reviewers have the time, tools, and expertise to do their jobs. Publishers and professional societies, including the Materials Research Society, should examine their implicit and explicit expectations of authors, reviewers, and editors. The MRS Bulletin itself is faced with these issues as we scan the peer-reviewed literature for news on materials research and as we choose topics and participants for themes. While peer review gives a level of validity, in our own selection and editing we will continue to question and to seek further understanding of the content we print on our pages.

This current chapter is over, but it has opened our eyes to the complexity of our fast-paced and intricately intertwined community. Whether one sees the system as succeeding by finding the misconduct or failing by letting it occur, we still can do better. We need not dwell on the past, but we would do well to learn from it and to strive for higher ground.

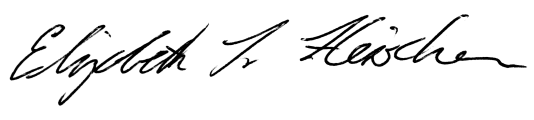

ELIZABETH L. FLEISCHER, EDITOR fleischer@mrs.org

\section{Statement from MRS on the Outstanding Young Investigator Award}

The Materials Research Society is considering a number of possible actions relating to the Outstanding Young Investigator award that was granted to Hendrik Schön in April of this year, before the first questions about his papers were made public. The final disposition of the award awaits a decision by the MRS Board of Directors, which is expected soon. For the record, MRS is pleased to note that through several attempts to reproduce the results, the scientific community was able to identify the flawed work. This self-checking process ensures that erroneous work, whether it is produced by genuine error or deliberate fraud, is always eventually corrected. 